\title{
Disponibilidade de ferro em misturas de alimentos com adição de alimentos com alto teor de vitamina $\mathrm{C}$ e de cisteína
}

\author{
Iron availability in food mixtures including foods with high vitamin $C$ and cysteine contents
}

\author{
Ana Paula FANTINI ${ }^{1}$, Solange Guidolin CANNIATTI-BRAZACA ${ }^{2 *}$, \\ Miriam Coelho SOUZA ${ }^{3}$, Debora Niero MANSI ${ }^{2}$
}

\begin{abstract}
Resumo
A disponibilidade do ferro é fator importante na dieta, pois a anemia ferropriva atinge grande parte da população mundial. A cisteína e a vitamina $C$ são fatores que melhoram sua absorção. A pesquisa teve por objetivos avaliar a disponibilidade de ferro em carne, feijão comum (Phaseolus vulgaris) e a combinação de arroz e tomate ao feijão, bem como analisar se o ácido fítico, o ácido oxálico e os taninos das combinações contendo feijão influenciam na disponibilidade de ferro de forma significativa. Os alimentos foram preparados para consumo e as amostras obtidas com a combinação de carne, feijão, arroz e tomate foram: A1 - carne bovina; A2 - feijão comum; A3 - feijão comum e tomate; A4 - feijão comum e arroz; e A5 - feijão comum, arroz e tomate. Foram realizadas as análises de taninos, ácido fítico, ácido oxálico, vitamina $\mathrm{C}$ e teor e diálise de ferro in vitro. Os teores de taninos, ácido fítico e ácido oxálico foram baixos para influenciar a disponibilidade do ferro. A diálise de 5,73 a 13,61\% indicando que a adição de cisteína e vitamina C em conjunto tem efeito maior do que quando presentes separadamente.
\end{abstract}

Palavras-chave: vitamina C; cisteína; feijão; tomate; arroz; carne.

\begin{abstract}
Iron availability is an important factor in the diet because iron deficiency anemia affects many people in the world. Cysteine and vitamin $\mathrm{C}$ are factors that increase its absorption. The research had the objectives of evaluating iron availability in meat, common beans (Phaseolus vulgaris) and the combination of rice and tomato with beans and to analyze if phytic acid, oxalic acid and tannins in the mixtures with beans affect iron availability significantly. The food was prepared as for consumption and the samples obtained by combining meat, beans, rice and tomato were: A1- meat; A2 - common beans; A3 - common beans and tomato; A4 - common beans and rice; and A5 - common beans, rice and tomato. Analyses of tannin, phytic acid, oxalic acid, and vitamin $\mathrm{C}$ contents and of in vitro iron content and dialysis were carried out. Low amounts of tannins, phytic acid and oxalic acid were found and they did not influence iron availability. Percentages from 5.73 to $13.61 \%$ dialysis were found, indicating that the combined addition of cysteine and vitamin C has an increased effect compared to when they are present separately.

Keywords: vitamin C; cysteine; bean; tomato; rice; meat.
\end{abstract}

\section{Introdução}

A anemia ferropriva atinge cerca de 2 bilhões de pessoas no mundo e é causada pelo desequilíbrio na quantidade biodisponível de ferro e sua necessidade orgânica. No Brasil, a anemia ferropriva foi apontada como a segunda maior deficiência causadora de doença na infância (ALMEIDA et al., 2004; SPINELLI et al., 2005).

A biodisponibilidade do ferro depende da composição e forma como os alimentos são consumidos e da combinação destes na dieta. $\mathrm{O}$ ferro heme presente na carne bovina, peixes, aves e vísceras apresenta alta biodisponibilidade, sendo absorvido pelo intestino em maior porcentagem (10 a 30\%) do que o ferro não heme. $\mathrm{O}$ ferro não heme, tem biodisponibilidade variável, porém sempre baixa. A biodisponibilidade desse tipo de ferro pode ser potencializada pelo consumo simultâneo de carnes, vísceras, alimentos ricos em ácidos orgânicos como o ascórbico, a vitamina A e carotenos (SANTOS et al., 2004).

O ácido ascórbico, quando ingerido na mesma refeição com o ferro não heme, potencializa a absorção. Ele mantém o ferro no estado ferroso e forma o quelato ferro-ascorbato, que é mais solúvel, por isso pronto para ser absorvido (GARCIA-CASAL et al., 1998).

A presença da vitamina $\mathrm{C}$ nas refeições aumenta a absorção do ferro mesmo em presença de alimentos que contenham fatores inibidores como fitatos, polifenóis, fosfatos, carbonatos e taninos pela formação do quelato ferro-ascorbato (ARANHA et al., 2000). O tomate é um alimento que possui grande

Recebido para publicação em 13/4/2007

Aceito para publicação em 14/12/2007 (002455)

1 Universidade Metodista de Piracicaba - UNIMEP

2 Departamento de Agroindústria, Alimentos e Nutrição, Escola Superior de Agricultura "Luiz de Queiroz" - ESALQ, Universidade de São Paulo - USP,

E-mail: sgcbraza@esalq.usp.br

${ }^{3}$ Faculdade de Ciências da Saúde, Universidade Metodista de Piracicaba - UNIMEP

${ }^{*}$ A quem a correspondência deve ser enviada 
quantidade de vitamina C, segundo a USDA (2007) o teor de vitamina $C$ varia de 9 a $16 \mathrm{mg} .100 \mathrm{~g}^{-1}$ nesse fruto.

Algumas substâncias presentes em alimentos, como os fitatos, os taninos e o ácido oxálico, possuem efeitos inibidores sobre o ferro não heme. Podem formar precipitados insolúveis que dificultam sua absorção.

As fibras não têm influência na absorção do ferro, e os cereais integrais só possuem efeito inibitório por conterem fitato em sua composição (OSÓRIO, 2002).

Alguns estudos apontam que aminoácidos livres encontrados no intestino, como a cisteína, aumentam a absorção da espécie férrica, pois formam quelatos solúveis com o ferro (HURRELL et al., 2006). O arroz é boa fonte de cisteína, com teor de $55 \mathrm{mg} .100 \mathrm{~g}^{-1}$ no arroz branco cozido (USDA, 2007).

Outros sugerem que os peptídeos liberados durante a digestão no estômago podem aumentar a solubilidade de ferro não heme melhorando sua absorção. Essas propriedades são atribuídas aos aminoácidos, especialmente os sulfurados como a cisteína. Ela se liga ao ferro mantendo-o solúvel e disponível para absorção (LYNCH, 1997).

Embora a anemia seja um dos maiores problemas mundiais de saúde pública, a média de ferro total presente na dieta de diversas regiões encontra-se acima das recomendações diárias necessárias para suprir o uso metabólico normal desse mineral, mostrando que a anemia é decorrente da baixa biodisponibilidade do ferro nos alimentos, principalmente o ferro não heme (BREITHAUPT; YAHIA; VILAZQUEZ, 2007; GUNNARSSON; THORSDOTTIR; PALSSON, 2007).

Os objetivos deste trabalho foram avaliar a disponibilidade de ferro em carne, feijão comum (Phaseolus vulgaris) e a combinação de arroz e tomate ao feijão; quantificar se o ferro contido no feijão em conjunto com tomate, que contém vitamina $C$, se equipara ao ferro disponível na carne; analisar se o ácido fítico, o ácido oxálico e os taninos influenciam na absorção desse mineral e verificar se os fatores antinutricionais contidos no feijão e no tomate interferem na absorção desse mineral.

\section{Material e métodos}

\subsection{Amostras}

Foram utilizados grãos de feijão comum (Phaseolus vulgaris) variedade Carioca, músculo bovino fresco, tomates vermelhos maduros crus e arroz branco, grão longo. Todas as amostras foram adquiridas no comércio local.

\subsection{Preparo das amostras}

\section{Feijão}

Foram utilizados $500 \mathrm{~g}$ de grãos de feijão, os quais foram lavados, divididos em dois Erlenmeyers em partes iguais e deixados sob maceração por 12 horas em água deionizada na proporção de 1:3 (feijão: água), sendo a água descartada e adicionada na proporção 1:2 (feijão: água) para posterior cozimento em autoclave por 10 minutos a $120^{\circ} \mathrm{C}$ (MOLINA et al., 1975). Após cozimento, o feijão foi homogeneizado em liqüidificador e preparadas as amostras.

\section{Músculo bovino}

O músculo bovino foi cozido em panela de aço inox aberta, em fogo médio, utilizando $500 \mathrm{~g}$ de músculo e $200 \mathrm{~mL}$ de água deionizada, que foi acrescentada aos poucos durante a cocção da carne. Após a cocção, a carne foi picada, homogeneizada e foram preparadas as amostras.

\section{Arroz}

O arroz foi cozido na proporção 2:1 (arroz: água), em panela de aço inox, em fogo médio utilizando água deionizada. Após cocção, o arroz foi homogeneizado e então foram preparadas as amostras.

\section{Tomate}

Foram utilizados aproximadamente $230 \mathrm{~g}$ de tomates maduros e frescos. Para fazer a determinação das amostras, estes foram picados e homogeneizados em liqüidificador, sendo todas as suas partes utilizadas (pele, sementes e polpa). As amostras foram preparadas, e a vitamina $\mathrm{C}$ quantificada imediatamente após o preparo das amostras.

\section{Preparo das amostras para análise}

Para as análises de diálise de ferro in vitro, as amostras dos diferentes tratamentos foram preparadas, homogeneizadas, armazenadas em freezer $\left(-20^{\circ} \mathrm{C}\right)$ e acondicionadas em sacos plásticos.

Já para as demais análises, as amostras foram desidratadas em estufa de 55 a $60^{\circ} \mathrm{C}$, moídas em moinhos de facas, tamisadas em peneira de 30 mesh, homogeneizadas, acondicionadas em embalagem plástica de polietileno e armazenadas a $4{ }^{\circ} \mathrm{C}$ para análises posteriores.

Todas as determinações foram realizadas em triplicata.

\section{Amostras}

As amostras de carne e de feijão foram analisadas isoladamente e também com acréscimo de arroz e tomate. Desse modo, foram avaliadas as seguintes amostras: A1 - carne bovina (100 g de carne bovina); A2 - feijão comum (100 g de feijão); A3 - feijão comum e tomate (100 g de feijão mais 228,21 g de tomate, o que corresponde a $50 \mathrm{mg}$ de vitamina C); A4 - feijão comum e arroz ( $100 \mathrm{~g}$ de feijão mais $4,5 \mathrm{~g}$ de arroz, o que corresponde a 2,5 mg de cisteína); e A5 - feijão comum, arroz e tomate (100 g de feijão, 4,5 g de arroz e 228,21 g de tomate).

\subsection{Fatores antinutricionais}

A determinação de fatores antinutricionais foi realizada em todas as amostras, exceto em A1 (carne bovina). 


\subsection{Taninos}

Os taninos foram analisados através da extração de 0,6 g para os tratamentos A3 e A5 e 1,5 g para os tratamentos A2 e A4 de amostra com $10 \mathrm{~mL}$ de metanol em agitação por 20 minutos e centrifugação a $4.000 \mathrm{rpm}$ por 20 minutos. Em seguida, foi realizada a reação colorimétrica, com solução de vanilina a $1 \%$ em metanol e $8 \%$ de $\mathrm{HCl}$ em metanol na proporção de 1:1 e com incubação a $30^{\circ} \mathrm{C}$ por 20 minutos. Então, a partir de $1 \mathrm{~mL}$ de extrato e $5 \mathrm{~mL}$ de solução de vanilina, foi realizada a leitura a $500 \mathrm{~nm}$ em espectrofotômetro, obtendo-se assim a concentração de taninos a partir de curva padrão de catequina, sendo os resultados expressos em mg.g-1 (PRICE et al., 1980).

\section{5 Ácido fítico}

Foi pesado 0,5 g de amostra e esta foi digerida em $10 \mathrm{~mL}$ de solução de $\mathrm{HCl} 0,65 \mathrm{~N}$ por 1 hora com agitação a cada 10 minutos, posteriormente centrifugada a $3.000 \mathrm{rpm}$ por 10 minutos. $\mathrm{Na}$ seqüência, foram pipetados $2 \mathrm{~mL}$ do sobrenadante em balão volumétrico de $25 \mathrm{~mL}$, sendo completado o volume com água. Foram pipetados $15 \mathrm{~mL}$ da solução do balão para bureta previamente preparada fazendo com que a solução eluísse através de resina à velocidade de uma gota por segundo, sendo este eluído descartado. Em seguida, foram pipetados $15 \mathrm{~mL}$ de solução $\mathrm{NaCl}$ 0,1 mol.L $\mathrm{L}^{-1}$ na coluna, sendo o eluído descartado também. Foram pipetados $15 \mathrm{~mL}$ de solução $\mathrm{NaCl} 0,7$ mol.L $\mathrm{L}^{-1}$ e foi recolhido o eluído em Bécher limpo de onde foram pipetados $5 \mathrm{~mL}$ em tubos de ensaio adicionados de $1 \mathrm{~mL}$ de reagente de Wade com agitação. Após 15 minutos de estabilização, foi realizada a leitura de absorbância a $500 \mathrm{~nm}$ em espectrofotômetro, obtendose assim o teor de ácido fítico a partir da construção de curva padrão, sendo os resultados expressos em $\mathrm{mg}$ de ácido fítico/g de amostra (GRYNSPAN et al., 1989).

\section{6 Ácido oxálico}

Foram pesados 2,5 g de amostra e colocados em $250 \mathrm{~mL}$ de solução $0,25 \mathrm{~N}$ de $\mathrm{HCl}$. A amostra foi mantida a $70^{\circ} \mathrm{C}$ por uma hora, resfriada e depois filtrada. Foram pipetados $5 \mathrm{~mL}$ em tubo de centrífuga, foram resfriados em banho de gelo por 10 minutos e adicionados de $1 \mathrm{~mL}$ de reagente de precipitação, com a realização de agitação. Foram mantidos refrigerados por cerca de 12 horas, sendo posteriormente centrifugados a $2.000 \mathrm{rpm}$ por 5 minutos. Foi descartado o sobrenadante e foi dissolvido o precipitado em $5 \mathrm{~mL}$ de solução $\mathrm{HCl}$ 0,25 N e resfriado novamente. Foi adicionado $1 \mathrm{~mL}$ de reagente de precipitação com agitação e novamente refrigerado por 12 horas. Em seguida, foi centrifugado por 5 minutos, sendo desprezado o sobrenadante. O precipitado foi lavado em $5 \mathrm{~mL}$ de solução de lavagem, foi centrifugado novamente, como já descrito, sendo descartado o sobrenadante. Os tubos com o precipitado foram secos a $100^{\circ} \mathrm{C}$

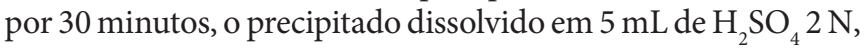
aquecido e titulado em $0,02 \mathrm{~N}$ de $\mathrm{KMnO}_{4}$ em microbureta até a persistência da cor rosa claro (Moir, 1953).

\section{7 Ácido ascórbico}

Foi dissolvido $0,4 \mathrm{~g}$ de tomate (com casca, polpa e sementes) em $50 \mathrm{~mL}$ de solução de ácido oxálico $0,4 \%$, filtrado em papel filtro com celite para retirada de cor e turvação. Foram transferidos $2 \mathrm{~mL}$ do filtrado para Erlenmeyer de $125 \mathrm{~mL}$, adicionados cerca de $50 \mathrm{~mL}$ de água destilada e titulado com solução de 2,6-dicloro-benzenoindofenol, até coloração rosa persistente por 15 segundos e anotado o volume gasto. Para a titulação padrão foi utilizado ácido ascórbico Os resultados foram expressos em mg de ácido ascórbico.100 g $\mathrm{g}^{-1}$ de amostra (JACOBS, 1958; LEME JUNIOR; MALAVOLTA, 1950).

\subsection{Teor de ferro e diálise in vitro}

Para a determinação do teor de ferro foram utilizados os ácidos nítrico e perclórico para a digestão nitro-perclórica das amostras a $50{ }^{\circ} \mathrm{C}$ por 10 a 15 minutos, a $100^{\circ} \mathrm{C}$ até digerir todo o material e atingir a temperatura de $150{ }^{\circ} \mathrm{C}$. Após resfriamento e diluição do material com água desmineralizada, foi realizada a leitura em espectrofotômetro de absorção atômica (SARRUGE; HAAG, 1974).

Para a diálise de ferro in vitro foram homogeneizados $15 \mathrm{~g}$ de amostra para A1 e $20 \mathrm{~g}$ da amostra para as demais amostras com $50 \mathrm{~mL}$ de água deionizada, devido à diferença de consistência das amostras. Em seguida, foi adicionado $\mathrm{HCl} 6 \mathrm{~N}$ até atingir $\mathrm{pH} 2$, na seqüência foi adicionado o $\mathrm{HCl} 0,01 \mathrm{~N}$ para completar o volume de $100 \mathrm{~mL}$. Foi realizada digestão com adição de 3,2 mL de solução $\mathrm{HCl}$-pepsina e incubação a $37^{\circ} \mathrm{C}$ em banho-maria, com agitação por 2 horas.

Para medir a acidez titulável foi utilizado béquer de $200 \mathrm{~mL}$ com $20 \mathrm{~g}$ do digerido, onde foram adicionados $5 \mathrm{~mL}$ de solução pancreatina-bile e esta solução titulada com $\mathrm{KOH} 0,5 \mathrm{~N}$ até $\mathrm{pH} 7,5$.

A diálise foi realizada colocando-se em um Bécher $20 \mathrm{~g}$ do digerido e a membrana de diálise, que foram previamente hidratados em água deionizada por 10 minutos, foi então colocado o volume de $\mathrm{NaHCO}_{3}$ 0,5 N (obtido na titulação descrita acima) diluído em $25 \mathrm{~mL}$ de água destilada. Os frascos foram então cobertos e colocados em banho-maria com agitação durante 30 minutos a $37^{\circ} \mathrm{C}$. Foram adicionados $5 \mathrm{~mL}$ de suspensão de bile pancreatina em cada frasco, seguindo ainda a incubação por mais 2 horas. O conteúdo do dialisável foi transferido para Bécheres e seus volumes foram completados para $25 \mathrm{~mL}$. Foram pipetados $5 \mathrm{~mL}$ do dialisado para tubo de centrífuga de $15 \mathrm{~mL}$ e adicionados 2,5 mL de solução precipitante de proteína. A mistura foi aquecida em banho-maria por 10 minutos e centrifugada a $2.000 \mathrm{rpm}$ por 10 minutos. Do sobrenadante, foram pipetados $5 \mathrm{~mL}$ e foram adicionados $2,5 \mathrm{~mL}$ de solução cromogêmica e, em seguida, agitados. Após 10 minutos, foi realizada a leitura a $533 \mathrm{~nm}$ em espectrofotômetro. A quantidade de ferro dialisado foi obtida através da utilização de curva padrão previamente preparada (WHITTAKER et al., 1989).

\subsection{Análise estatística}

Os dados obtidos foram submetidos à análise de variância (ANOVA). Para verificar quais tratamentos diferiram, foi aplicado o teste de Tukey para realizar comparações pareadas das médias dos tratamentos, estabelecendo-se o nível mínimo de significância de $5 \%(\mathrm{p} \leq 0,05)$. Utilizou-se o software SAS Institute (SAS INSTITUTE, 1999). 


\section{Resultados e discussão}

Os resultados obtidos para as diferentes amostras são apresentados nas Tabelas 1 a 3 .

A quantidade de taninos encontrada na amostra de feijão foi o que determinou a quantidade em todas as amostras, não apresentando diferenças significativas entre elas (Tabela 1).

A quantidade de taninos encontrada por Villavicencio et al. (2000) foi de 1,8 mg.g ${ }^{-1}$ de feijão cru. Na Tabela 1 os valores apresentados estão em base fresca e as amostras foram cozidas, o que diminui os teores de taninos das amostras. Oliveira et al. (2001) observaram uma redução do teor de taninos no processo de cozimento e que o melhor tratamento para retirada de taninos foi a maceração, seguida da cocção sem a água de maceração, onde houve redução de $88 \%$ de taninos na amostra. Esse procedimento foi utilizado para o preparo do feijão.

Apesar da dieta do ser humano possuir vários alimentos que contêm taninos, incluindo leguminosas, os efeitos dos mesmos em seres humanos ainda são desconhecidos devido à limitação de estudos nesta área, embora substâncias formadoras de complexos com compostos nitrogenados, como os taninos, provavelmente devam reduzir a digestibilidade de proteínas, inibir ações enzimáticas e interferir na absorção de ferro (SILVA; SILVA, 1999), dependendo das quantidades e condições do meio.

Tabela 1. Teores de taninos, ácido fítico e ácido oxálico encontrados nas amostras de carne, feijão arroz e tomate.

\begin{tabular}{cccc}
\hline Amostras $^{1}$ & $\begin{array}{c}\text { Taninos } \\
\left(\mathrm{mg} \cdot \mathrm{g}^{-1}\right)\end{array}$ & $\begin{array}{c}\text { Ácido fítico } \\
\left(\mathrm{mg} \cdot \mathrm{g}^{-1}\right)\end{array}$ & Ácido oxálico (\%) \\
\hline A2 & $0,10 \pm 0,00^{2 \mathrm{a} 3}$ & $1,69 \pm 0,02^{\mathrm{b}}$ & $0,09 \pm 0,01^{\mathrm{a}}$ \\
A3 & $0,15 \pm 0,01^{\mathrm{a}}$ & $0,94 \pm 0,01^{\mathrm{d}}$ & $0,04 \pm 0,00^{\mathrm{b}}$ \\
A4 & $0,11 \pm 0,00^{\mathrm{a}}$ & $1,99 \pm 0,02^{\mathrm{a}}$ & $0,04 \pm 0,00^{\mathrm{b}}$ \\
A5 & $0,14 \pm 0,00^{\mathrm{a}}$ & $1,03 \pm 0,04^{\mathrm{c}}$ & $0,03 \pm 0,01^{\mathrm{b}}$ \\
\hline
\end{tabular}

${ }^{1} \mathrm{~A} 2$ - feijão comum; A3 - feijão comum e tomate; A4 - feijão comum e arroz; e A5 - feijão comum, arroz e tomate; ${ }^{2}$ média de três repetições \pm desvio padrão; $\mathrm{e}^{3}$ letras diferentes nas colunas indicam diferença estatística entre as amostras $(\mathrm{p} \leq 0,05)$.

Tabela 2. Teor de ácido ascórbico encontrado nas amostras.

\begin{tabular}{cc}
\hline Amostras $^{1}$ & Ácido ascórbico $\left(\mathrm{mg.} 100 \mathrm{~g}^{-1}\right)$ \\
\hline A2 & $9,9 \pm 2,0^{2 \mathrm{~b} 3}$ \\
A3 & $15,87 \pm 2,1^{\mathrm{a}}$ \\
A4 & $8,78 \pm 0,0^{\mathrm{b}}$ \\
A5 & $19,43 \pm 2,1^{\mathrm{a}}$ \\
\hline
\end{tabular}

${ }^{1} \mathrm{~A} 2$ - feijão comum; A3 - feijão comum e tomate; A4 - feijão comum e arroz; e A5 - feijão comum, arroz e tomate; ${ }^{2}$ média de três repetições \pm desvio padrão; $\mathrm{e}^{3}$ letras diferentes nas colunas indicam diferença estatística entre as amostras $(\mathrm{p} \leq 0,05)$.

Tabela 3. Teor de ferro e porcentagem de ferro dialisável nas amostras de carne, feijão, arroz e tomate.

\begin{tabular}{ccc}
\hline Amostras $^{1}$ & Teor de ferro $\left(\mu{\left.\mathrm{g} \cdot \mathrm{g}^{-1}\right)}\right.$ & Ferro dialisável $(\%)$ \\
\hline A1 & $8,86 \pm 2,0^{2 \mathrm{ab} 3}$ & $8,78 \pm 0,1^{\mathrm{b}}$ \\
A2 & $17,11 \pm 4,7^{\mathrm{a}}$ & $6,23 \pm 0,0^{\mathrm{c}}$ \\
A3 & $12,02 \pm 5,1^{\mathrm{a}}$ & $7,78 \pm 0,1^{\mathrm{bc}}$ \\
A4 & $17,45 \pm 5,0^{\mathrm{a}}$ & $5,73 \pm 0,0^{\mathrm{c}}$ \\
A5 & $6,99 \pm 3,4^{\mathrm{b}}$ & $13,61 \pm 0,5^{\mathrm{a}}$ \\
\hline
\end{tabular}

${ }^{1} \mathrm{~A} 1$ - carne bovina; A2 - feijão comum; A3 - feijão comum e tomate; A4 - feijão comum e arroz; A5 - feijão comum, arroz e tomate; ${ }^{2}$ média de três repetições \pm desvio padrão; $\mathrm{e}^{3}$ letras diferentes nas colunas indicam diferença estatística entre as amostras $(\mathrm{p} \leq 0,05)$.
Quanto ao ácido fítico foram encontrados valores de

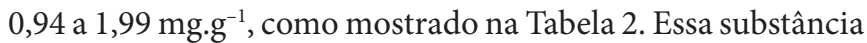
se liga aos metais, especialmente ao ferro. Isso demonstra que possui ação antioxidante e anticarcinogênica devido à formação de quelato com esse mineral. Porém é comprovado que minerais como o ferro, cálcio, zinco e cobre em presença de ácido fítico têm absorção reduzida, formando complexos menos solúveis (SILVA; SILVA, 1999).

Brigide e Canniatti-Brazaca (2006) encontraram 9,55 mg de ácido fítico por grama de amostra de feijão e verificaram que a cocção e tratamento térmico não alteram o índice de fitatos contidos no feijão, no entanto, a maceração por 12 horas reduz o teor de fitatos em $31 \%$ e a maceração por 24 horas reduz em $16 \%$. Oliveira et al. (2003) encontraram 14,7 mg de ácido fítico por grama de feijão cru. Os dados são superiores aos encontrados na Tabela 1 .

A quantidade de ácido oxálico encontrado no estudo (Tabela 1) foi um valor próximo ao encontrado por Proulx et al. (1993).

Fernandez-Ruiz et al. (2004) encontraram variação de 0,027 a $0,258 \%$ de ácido oxálico no tomate, porém não houve influência na quantidade encontrada devido à pequena proporção de tomate nas amostras. $\mathrm{O}$ feijão foi o alimento que mais influenciou na quantidade de ácido oxálico nas amostras (Tabela 1), a amostra só com feijão apresentou o maior valor de ácido oxálico.

Para a vitamina C nota-se que em A2 e A4 os valores foram iguais, indicando que o arroz não interferiu na vitamina $C$ existente na amostra. Em A3 e A5 encontrou-se valor maior de ácido ascórbico, pois são as duas amostras que contêm tomate. De acordo com dados encontrados na tabela USDA (2005), há 19,1 mg de ácido ascórbico em $100 \mathrm{~g}$.

Os teores e as porcentagens de ferro dialisável encontrados nas amostras podem ser vistos na Tabela 3.

Considerando os alimentos de forma isolada, pode ser observado que o feijão (A2) apresentou menor porcentagem de ferro dialisável que a carne (A1) (Tabela 3). Brigide e Canniatti-Brazaca (2006) e Mechi e Canniatti-Brazaca (2006) encontraram valores de 5,33 e 1,40\% para feijão carioca e feijão preto. A menor porcentagem de diálise do ferro em feijão preto provavelmente se deve à maior quantidade de polifenóis.

A porcentagem de ferro disponível em A3 não apresentou alteração em relação a A2, mesmo A3 com adição de vitamina C. O mesmo ocorreu para a adição de cisteína na A4. Entretanto para A5 houve aumento significativo na disponibilidade de ferro em relação às demais misturas. Este resultado está de acordo com o encontrado por Moura e Canniatti-Brazaca (2006), e indica que a presença de cisteína e vitamina $\mathrm{C}$ promove aumento da diálise, independentemente da origem do nutriente, cujos comportamentos foram semelhantes. As misturas que contêm substâncias que interferem negativamente na disponibilidade de ferro não sofreram inibição devido, provavelmente, aos baixos teores dessas substâncias (Tabela 1).

Estudos mostram que os aminoácidos e os peptídeos influenciam na absorção do ferro e realçam a ação da cisteína 
neste processo (HURREL et al., 2007). A cisteína aumenta a solubilidade do ferro quando adicionada a uma solução contendo ferro insolúvel. Mas este efeito é diferente do provocado pela vitamina $\mathrm{C}$, que deve ser combinada com o ferro tornando-o solúvel em pH 2 ( $\mathrm{pH}$ do estômago) para reduzi-lo e solubilizá-lo e, para que este possa ser absorvido no intestino (COSTA et al., 2001; GLAHN, 1997).

\section{Conclusões}

A quantidade de antinutricionais encontrada em A2, A3, A4 e A5 não exerceu efeito inibitório na biodisponibilidade de ferro dessas amostras se comparado com a carne (A1). Porém, notou-se que os acréscimos de cisteína e vitamina $\mathrm{C}$ presentes no arroz e no tomate, respectivamente, resultaram em aumento significativo na disponibilidade de ferro ao compararmos com A2. Contudo, a adição de vitamina $\mathrm{C}$ do tomate em A3 e de cisteína do arroz em A4 não ocasionou aumento significativo na biodisponibilidade do ferro.

\section{Referências bibliográficas}

ALMEIDA, C. A. N. et al. Fatores associados à anemia por deficiência de ferro em crianças pré-escolares brasileiras. Jornal de Pediatria, Rio de Janeiro, v. 80, n. 3, p. 229-234, maio/jun. 2004.

ARANHA, F. Q. et al. O papel da vitamina C sobre as alterações orgânicas no idoso. Revista de Nutrição, Campinas, v. 13, n. 2, p. 89-97, maio/ago. 2000.

BREITHAUPT, D. E.; YAHIA, E. M.; VILAZQUEZ, F. J. V. Comparison of the absorption efficiency of alpha and beta-cryptoxantin in female wistar rats. British Journal of Nutrition, Cambridge, v. 97, n. 2, p. 329-336, feb. 2007.

BRIGIDE, P.; CANNIATTI-BRAZACA, S. G. Antinutrients and in vitro availability of iron in irradiated common beans (Phaseolus vulgaris). Food Chemistry, Oxford, v. 98, n. 1, p. 85-89, jan. 2006.

COSTA, M. J. C. et al. Efeito da suplementação com acerola nos níveis sanguíneos de vitamina $\mathrm{C}$ e de hemoglobina em crianças pré-escolares. Revista de Nutrição, Campinas, v. 14, n. 1, p. 13-20, jan./abr. 2001.

FERNANDEZ-RUIZ, V. et al. Internal quality characterization of fresh tomato fruits. Hortscience, Alexandria, v. 39, n. 2, p. 339-345, apr. 2004.

GARCIA-CASAL, M. N.; LAYRISSE, M. Absorción del hierro de los alimentos: papel de la vitamina A. Archivos Latinoamericanos de Nutricion, Caracas, v. 48, n. 3, p. 191-195, sept. 1998.

GLAHN, R. P.; VAN CAMPEN, D. R. Iron uptake is enhanced in Caco-2 cell monolayers by cysteine and reduced cysteinyl glycine. Journal of Nutrition, Bethesda, v. 127, n. 4, p. 642-647, apr. 1997.

GRYNSPAN, F.; CHERYAN, M. Phytate-calcium interaction with soy protein. Journal of the American Oil Chemists' Society, Champaign, v. 66, n. 1, p. 93-97, jan. 1989.

GUNNARSSON, B. S.; THORSDOTTIR, I.; PALSSON, G. Associations of iron status with dietary and other factors in 6-year-old children. European Journal of Clinical Nutrition, London, v. 61, n. 3, p. 398-403, mar. 2007.

HURRELL, R. F. et al. Meat protein fractions enhance nonheme iron absorption in humans. Journal of Nutrition, Bethesda, v. 136, n. 11, p. 2808-2812, nov. 2006.

JACOBS, M. B. The chemical analysis of foods and food products. New York: Van Nostrand, 1958. 979 p.
LEME JUNIOR, J.; MALAVOLTA, E. Determinação fotométrica de ácido ascórbico. Anais da ESALQ, v. 7, p. 115-129, 1950.

LYNCH, S. R. Interaction of iron witch other nutrients. Nutrition Review, Lawrence, v. 55, n. 4, p. 102-110, apr. 1997.

MOIR, K.W. Determination of oxalic acid in plant Queensland. The Journal of Agricultural Science, New York, v. 10, n. 1, p. 1-3, jan. 1953.

MOLINA, M. R.; FUENTE, G.; BRESSANI, R. Interrelationships between storage, soaking time, cooking time, nutritive value and other characteristics of the black bean (Phaseolus vulgaris). Journal of Food Science, Chicago, v. 40, n. 3, p. 587-591, mar. 1975.

MOURA, N. C.; CANNIATTI-BRAZACA, S. G. Avaliação da disponibilidade de ferro de feijão comum (Phaseolus vulgaris L.) em comparação com a carne bovina. Ciência e Tecnologia de Alimentos, Campinas, v. 26, n. 2, p. 270-276, abr./jun. 2006.

OLIVEIRA, A. C. et al. O processamento doméstico do feijão comum ocasionou uma redução nos fatores antinutricionais fitatos, taninos, no teor de amido e em fatores de flatulência rafinose, estaquiose e verbascose. Archivos Latinoamericanos de Nutricion, Caracas, v. 51, n. 3, p. 276-283, set. 2001.

OLIVEIRA, A. C. et al. Adições crescentes de ácido fítico à dieta não interferiram na digestibilidade da caseína e no ganho de peso em ratos. Revista de Nutrição, Campinas, v. 16, n. 2, p. 211-217, abr./ jun. 2003.

OSÓRIO, M. M. Fatores determinantes da anemia em crianças. Journal de Pediatria, Rio de Janeiro, v. 78, n. 4, p. 269-278, jul./ago. 2002.

PRICE, M. L.; HAGERMAN, A. E.; BUTLER, L. G. Tannin content of cowpeas, chickpeas, pigeonpeas and mung beans. Journal of Agriculture and Food Chemistry, Washington, v. 28, n. 2, p. 459-461, feb. 1980.

PROULX, W. R.; WEAVER, C. M.; BOCK, M. A. Trypsin-inhibitor activity and tannin content do not affect calcium bioavailability of 3 commonly consumed legumes. Journal of Food Science, Chicago, v. 58, n. 2, p. 382-384, mar./apr. 1993.

SILVA, M. R.; SILVA, A. A. P. Aspectos nutricionais de fitatos e taninos. Revista de Nutrição, Campinas, v. 12, n. 1, p. 21-32, jan./ apr. 1999.

SANTOS, I. et al. Prevalência e fatores associados à ocorrência de anemia entre menores de seis anos de idade em Pelotas, RS. Revista Brasileira de Epidemiologia, São Paulo, v. 7, n. 4, p. 403-415, dez. 2004.

SARRUGE, J. R.; HAAG, H. P. Análises químicas em plantas. Piracicaba: USP/ESALQ, 1974.

SAS INSTITUTE - Statistical Analysis System. Sas/Qc Software: usage and referente. Version 8.0. Cary: SAS, 1999.

SPINELLI, M. G. N. et al. Fatores de risco para anemia em crianças de 6 a 12 meses no Brasil. Revista Panamericana de Salud Publica, Washington, v. 17, n. 2, p. 84-91, feb. 2005.

USDA. National Nutrient Database for Standard Reference, Release 18, 2005. Disponível em: <www.nal.usda.org.br>. Acesso em: 3 abr. 2007.

VILLAVICENCIO, A. L. C. H. et al. Effect of irradiation on antinutrients (total phenolics, tannins and phytate) in Brazilian beans. Radiation Physics and Chemistry, Oxford, v. 57, n. 3-6, p. 289-293, mar. 2000.

WHITTAKER, P.; FOX, M. R. S; FORBES, A. L. In vitro prediction of iron bioavailability for food fortification. Nutrition Reports International, Wolburn, v. 39, n. 6, p. 1205-1215, jun. 1989. 